\title{
OPTIMALISASI PENGELOLAAN USAHA LABORATORIUM LAPANG TERPADU FAKULTAS PERTANIAN UNIVERSITAS LAMPUNG MENGGUNAKAN METODE LINEAR PROGRAMMING
}

\author{
BUSINESS MANAGEMENT OPTIMIZATION OF INTEGRATED FIELD \\ LABORATORY OF AGRICULTURAL FACULTY OF LAMPUNG UNIVERSITY \\ USING A LINEAR PROGRAMMING METHOD
}

\author{
Wahyu Ratnaningsih $^{1 凶}$, Sandy Asmara ${ }^{1}$, Winda Rahmawati ${ }^{1}$, Agus Haryanto ${ }^{1}$, \\ Dwi Dian Novita ${ }^{1}$ \\ ${ }^{1}$ Jurusan Teknik Pertanian, Fakultas Pertanian, Universitas Lampung \\ ${ }^{\square}$ Komunikasi Penulis, e-mail: wahyuratnaningsih692@gmail.com \\ DOI: http://dx.doi.org/10.23960/jtep-l.v7i1.25-34 \\ Naskah ini diterima pada 21 Maret 2018; revisi pada 16 April 2018; \\ disetujui untuk dipublikasikan pada 26 April 2018
}

\begin{abstract}
Integrated field laboratory (Lab. LT.) is one of laboratory in Agricultural Faculty University of Lampung. University of lampung laboratory $67.000 \mathrm{~m}^{2}$ area, that were divided into 5 parts suchas main part that land business, land research and lab work, land cattle, fish ponds, and unused land. The purpose of research is formulate linear programming mathematics model and calculate the profit optimal in the management of the lab.LT. Research used the model linear programming based on a method of simplex with the qm for windows software. The research result showed that the assumption profit data is greater than the real data conditions of lab. LT. Resarch results showed assumption data profit was greater than real data profit, 6 months profit was Rp.39.703.330 if Zmax value $\left(\mathrm{x}_{2}\right)$ equal to zero with provison business land area added $1 \%$ and from previous land area the fish pond area added 2,22\%. Whilw based on 6 months's assumption data profit was Rp.51.333.330, with 1,25\% research and lab work land added and 2,22\% fish pond area added from current area used. Profit margin between assumtion and real data is Rp.11.630.000 for 6 month.
\end{abstract}

Keywords: Optimization, operations research, linear programming, simpleks method, QM for windows

\begin{abstract}
ABSTRAK
Laboratorium lapang terpadu (Lab. LT.) merupakan salah satu laboratorium yang terdapat di Fakultas Pertanian Universitas Lampung. Memiliki luas $67.000 \mathrm{~m}^{2}$, yang terbagi menjadi 5 bagian utama yaitu lahan usaha, lahan penelitian dan praktikum, lahan ternak, kolam ikan, dan lahan tidak terpakai. Tujuan dari penelitian ini yaitu merumuskan formulasi matematika model linear programming dan menghitung nilai keuntungan optimal bagi pengelolaan Lab. LT. Penelitian menggunakan model linear programming berdasarkan metode simpleks dengan bantuan software QM For Windows. Hasil penelitian menunjukan bahwa nilai keuntungan data asumsi lebih besar dari data asli berdasarkan kondisi Lab. LT. Keuntungan yang diperoleh setiap 6 bulannya jika nilai Zmax $\left(\mathrm{x}_{2}\right)$ sama dengan nol Rp.39.703.330, dengan ketentuan luas lahan usaha ditambah 1\% dari luas sebelumnya dan untuk kolam ikan ditambah 2,22\% dari luas sebelumnya. Berdasarkan nilai asumsi keuntungan yang akan diperoleh setiap 6 bulannya yaitu Rp.51.333.330, dengan ketentuan luas lahan penelitian dan praktikum ditambah $1,25 \%$ dari luas lahan sebelumnya dan untuk kolam ikan ditambah 2,22\% dari luas kolam yang digunakan sebelumnya. Selisih keuntungan yang diperoleh dari data asli dan data asumsi sebesar Rp.11.630.000 setiap 6 bulan.
\end{abstract}

Kata kunci: Optimalisasi, riset operasional, linear programming, metode simpleks, QM for windows. 


\section{PENDAHULUAN}

Fakultas Pertanian Universitas Lampung merupakan fakultas yang memiliki 1 program diploma (D3) dan 7 program sarjana (S1). Pada awalnya fakultas pertanian memiliki jumlah laboratorium sebanyak 25 laboratorium, namun pada akhir 2005 setelah adanya lokakarya manajemen laboratorium, maka terjadi penggabungan beberapa laboratorium dalam satu manajemen. Sehingga pada tahun 2006 Fakultas Pertanian hanya memiliki 19 Laboratorium. Seluruh laboratorium tersebut dibawah pengelolaan setiap jurusan yang terdapat di fakultas tersebut. Akan tetapi terdapat satu laboratorium utama yang dikelolah langsung oleh pihak Fakultas Pertanian yang disebut sebagai Laboratorium Lapang Terpadu (Lab. LT.).

Lab. LT. digunakan sebagai sarana penelitian dan praktikum bagi mahasiswa maupun dosen, agar dapat membentuk lulusan Fakultas Pertanian Universitas Lampung yang kompeten. Laboratorium tersebut memiliki luas yaitu 6,7 hektar yang terdiri dari lahan usaha, lahan praktikum dan penelitian, lahan bangunan, dan lahan ternak serta kolam. Adanya Lab. LT. ini diharapkan akan dapat membantu meningkatkan pendapatan bagi Fakultas Pertanian. Namun selama ini ternyata pengelolaan dan pemanfaatan Lab. LT. masih belum maksimal.

Terkait dengan masalah pengelolaan Lab. LT. yang belum optimum, tentu dibuat suatu penelitian tentang upaya perhitungan analisis optimalisasi pendapatan dalam pengelolaan Lab. LT., dengan menerapkan teori-teori dalam riset operasional (operations research) yaitu suatu model kuantitatif atau matematik yang digunakan dalam pengambilan keputusan manajemen yang tentunya menggunakan konsep optimalisasi (Yamit, 2012). Untuk mendapatkan penyelesaian optimal tersebut maka dikembangkanlah suatu metode analisis yang disebut dengan metode program linear (linear programming). Metode ini merupakan metode yang tepat untuk diterapkan sebagai implementasi dalam optimalisasi pengelolaan karena mudah dipahami untuk memecahkan masalah yang dialami Lab. LT .
Pengelolaan Lab. LT. saat ini masih belum optimal, sehingga akan dilakukan suatu analisis bagaimana cara optimalisasi pendapatan dalam pengelolaan Lab. LT. dengan menerapkan ilmu mengenai riset operasional (operations research) menggunakan metode linear programming sehingga akan diperoleh keuntungan yang maksimal.

Adapun tujuan yang diharapkan dari penelitian ini yaitu merumuskan formulasi matematika linear programming bagi pengelolaan Lab. LT, dan menghitung nilai keuntungan yang optimal dalam pengelolaan Lab. LT. Fakultas Pertanian Universitas Lampung.

\section{BAHAN DAN METODE}

\subsection{Alat dan Bahan}

Peralatan yang digunakan dalam penelitian ini yaitu alat tulis, perekam suara, kamera, leptop serta software QM For Windows. Sedangkan bahan yang digunakan dalam penelitian ini yaitu data primer berupa hasil survey serta wawancara dan data sekunder yang berupa data pendapatan dan data pengelolaan Lab. LT. dari pihak pengelolaan.

\subsection{Metode Penelitian}

Metode yang digunakan dalam penelitian ini yaitu metode analisis campuran menggunakan data kuantitatif dan kuaitatif. Dalam penelitian ini terdapat beberapa tahapan-tahapan penelitian yaitu:

1. Tahap Persiapan

Tahap ini merupakan tahap awal dari penelitian, yaitu mencakup identifikasi masalah dan pengumpulan informasi awal yang berguna bagi penelitian.

2. Tahap Pengumpulan Data

Tahap ini merupakan tahap pengumpulan berbagai data dan informasi yang berguna bagi penelitian, untuk kemudian diolah dan dianalisis sesuai dengan metode penelitian yang ada. Adapun data yang digunakan dalam penelitian ini adalah data primer dan data sekunder. Data primer merupakan data yang berupa teks atau rekaman hasil wawancara, data ini diperoleh dari survei dan wawancara langsung ke Lab. LT., Fakultas Pertanian, Universitas Lampung. Sedangkan data sekunder yaitu berupa data 


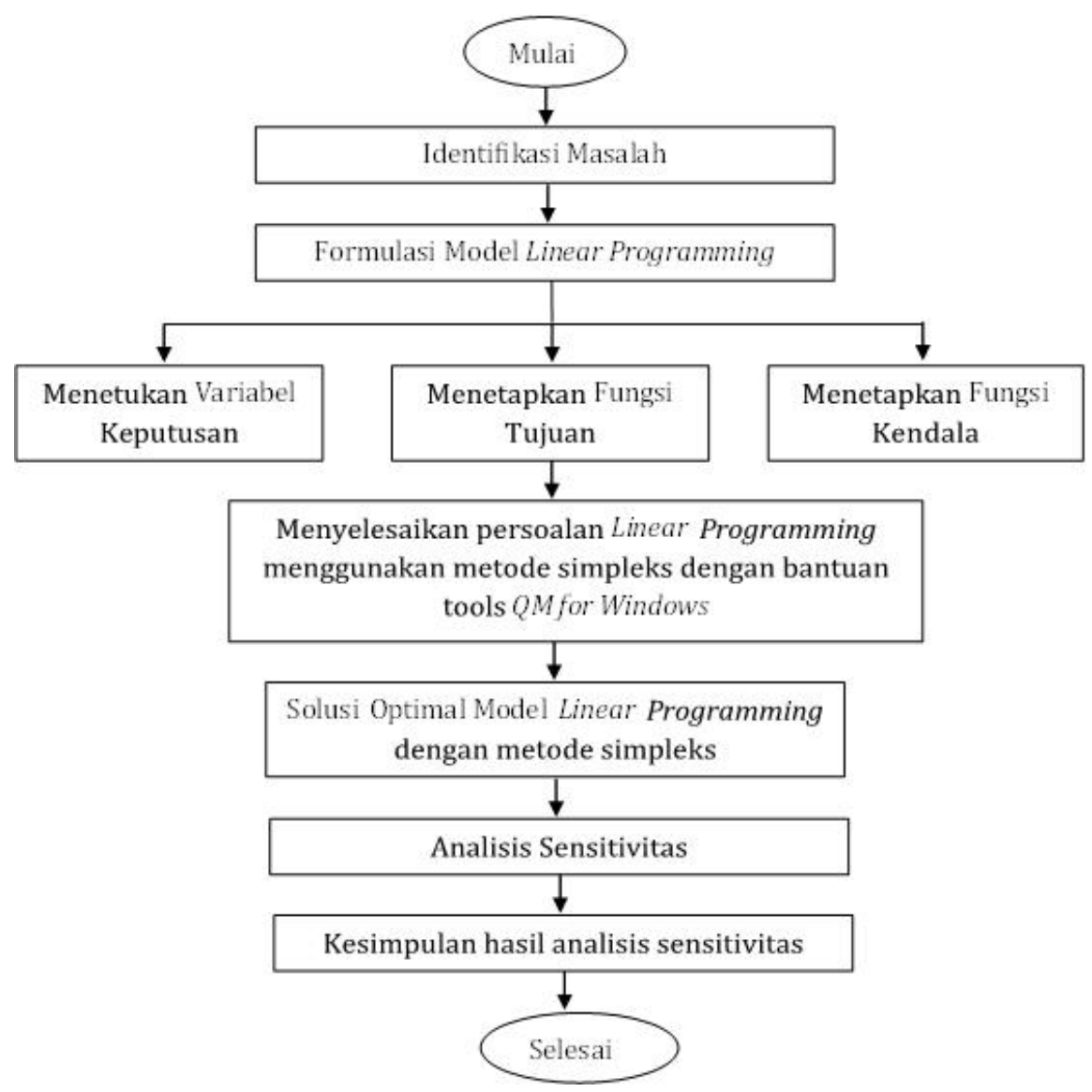

Gambar 1. Diagram Tahap Analisis

pendapatan, tenaga kerja dan data pengelolaan yang sudah tercatat di Lab. LT.

3. Tahap Analisis

Tahap ini berisi tentang analisis terhadap datadata yang terkumpul dan yang telah diolah untuk menentukan nilai optimalisasi pengelolaan serta pendapatan maksimumnya. Rangkaian tahapan analisis untuk penentuan optimalisasi pengelolaan Lab. LT. menggunakan model linear programming dapat dilihat pada Gambar 1.

Perumusan model matematik linear programming untuk fungsi tujuan dan fungsi kendala yaitu:

$$
\operatorname{Zmax}=\mathrm{c}_{1} \mathrm{x}_{1}+\mathrm{c}_{2} \mathrm{x}_{2}+\mathrm{c}_{3} \mathrm{x}_{3}+\mathrm{c}_{4} \mathrm{x}_{4}+\mathrm{c}_{5} \mathrm{x}_{5}
$$

Fungsi Kendala :

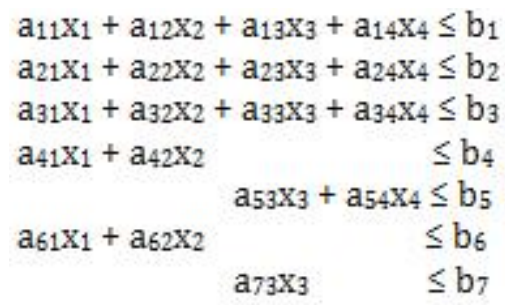

Keterangan :

Zmax = Nilai Optimal

$\mathrm{c}=$ Koefisien (rupiah yang didapat/ keuntungan) setiap variabel

$\mathrm{x} \quad=$ Variabel Keputusan

$\mathrm{x}_{1}=$ Lahan usaha

$\mathrm{x}_{2}=$ Lahan praktikum dan penelitian

$\mathrm{x}_{3}=$ Lahan ternak

$\mathrm{x}_{4}=$ Kolam ikan

$\mathrm{x}_{5}=$ Lahan tidak terpakai

$a_{i j}$ dan $_{b_{i}}=$ Koefisien Fungsi Kendala (Luas Lahan, kebutuhan tenaga kerja, kebutuhan air, kebutuhan pestisida, pakan, pupuk, dan vaksin.

\section{HASIL DAN PEMBAHASAN}

\subsection{Gambaran Umum Laboratorium Lapang Terpadu}

Laboratorium Lapang Terpadu Fakultas Pertanian Universitas Lampung merupakan hamparan lahan yang digunakan untuk praktikum dan penelitian oleh mahasiswa dan dosen Fakultas Pertanian Universitas Lampung. Lokasinya cukup strategis dan berpotensi untuk 
dikembangkan. Luas keseluruhan lahannya yaitu $6,7 \mathrm{Ha}$, dimana $60 \%$ dari lahan tersebut digunakan sebagai tempat praktikum dan penelitian dan $40 \%$ nya merupakan tempat usaha.

\subsection{Pemodelan Linear Programming Laboratorium Lapang Terpadu}

Penentuan model matematika berdasarkan linear programming yaitu dengan cara menentukan variabel keputusan, merumuskan funsi tujuan dan batasannya. Terdapat lima variabel keputusan yaitu lahan usaha $\left(\mathrm{x}_{1}\right)$, lahan penelitian dan praktikum $\left(\mathrm{x}_{2}\right)$, lahan ternak $\left(\mathrm{x}_{3}\right)$, kolam ikan $\left(\mathrm{x}_{4}\right)$, dan lahan tidak terpakai $\left(\mathrm{x}_{5}\right)$. Menentukan formulasi dari fungsi tujuan, sebelumnya dihitung laba dari setiap variabel yang ada, dapat dilihat pada tabel-tabel sebelumnya.

Karena nilai $\mathrm{x}_{2}$ sama dengan nol (0), maka akan dibuat sebuah asumsi untuk lahan penelitian dan praktikum yaitu untuk yang melakukan praktikum di Lab. LT. ada biaya pengelolaan sebanyak Rp.500.000 per kelasnya dan untuk yang melakukan penelitian di Lab. LT. dan biaya pengelolaan sebesar Rp.100.000 per orangnya. Nilai tersebut akan digunakan sebagai pembanding untuk mengetahui keuntungan maksimum jika nilai $x_{2}$ tidak sama dengan nol (0). Nilai asumsi tersebut dapat dilihat pada Tabel 2.

Jadi berdasarkan tabel dan penjelasan diatas, maka diperoleh fungsi tujuan untuk (Zmax) data asli yaitu:

$\mathrm{Zmax}=9.370 .000 \mathrm{x}_{1}+0 \mathrm{x}_{2}+7.581 .800 \mathrm{x}_{3}+$ $13.650 .000 \mathrm{x}_{4}+0 \mathrm{x}_{5}$

Sedangkan untuk fungsi tujuan (Zmax) data asumsi yaitu sebagai berikut:

$Z \max =9.370 .000 x_{1}+16.800 .000 x_{2}+7.581 .800$ $x_{3}+13.650 .000 x_{4}+0 x_{5}$

Tabel 1. Keuntungan setiap variabel

\begin{tabular}{lrrr}
\hline \multicolumn{1}{c}{ Variabel (X) } & $\begin{array}{c}\text { Pengeluaran } \\
\text { (Rp)/6 bulan }\end{array}$ & $\begin{array}{c}\text { Pendapatan } \\
\text { (Rp)/6 bulan }\end{array}$ & $\begin{array}{c}\text { Laba/3 bulan } \\
\text { (Rp)/6 bulan }\end{array}$ \\
\hline Lahan di usahakan & 8.405 .000 & 17.775 .000 & 9.370 .000 \\
Lahan praktikum/penelitian & 0 & 0 & 0 \\
Lahan ternak & 19.015 .000 & 26.596 .800 & 7.581 .800 \\
Kolam ikan & 17.287 .500 & 30.937 .500 & 13.650 .000 \\
Lahan tidak terpakai & 0 & 0 & 0 \\
\hline
\end{tabular}

Tabel 2. Asumsi untuk keuntungan apabila nilai $\mathrm{x}_{2}$ tidak sama dengan nol (0)

\begin{tabular}{lrrr}
\hline \multicolumn{1}{c}{ Variabel (X) } & $\begin{array}{c}\text { Pengeluaran } \\
\text { (Rp) }\end{array}$ & $\begin{array}{c}\text { Pendapatan } \\
\text { (Rp) }\end{array}$ & $\begin{array}{c}\text { Laba/3bulan } \\
\text { (Rp) }\end{array}$ \\
\hline Lahan di usahakan & 8.405 .000 & 17.775 .000 & 9.370 .000 \\
Lahan praktikum/penelitian & 0 & 16.800 .000 & 16.800 .000 \\
Lahan ternak & 19.015 .000 & 26.596 .800 & 7.581 .800 \\
Kolam ikan & 17.287 .500 & 30.937 .500 & 13.650 .000 \\
Lahan tidak terpakai & 0 & 0 & 0 \\
\hline
\end{tabular}

Tabel 3. Kebutuhan bahan baku untuk pengelolaan lahan

\begin{tabular}{lrrrrrr}
\hline \multicolumn{1}{c}{ Fungsi Kendala } & $\mathrm{X} 1$ & $\mathrm{X} 2$ & $\mathrm{X} 3$ & $\mathrm{X} 4$ & $\mathrm{X} 5$ & \multicolumn{1}{c}{ RHS } \\
\hline Luas Lahan $\left(\mathrm{m}^{2}\right)$ & 13.174 & 24.120 & 400 & 478 & 28.828 & 67.000 \\
Tenaga Kerja (orang) & 1 & 1 & 2 & 2 & 0 & 6 \\
Kebutuhan Air & 438.750 & 900.000 & 3.600 & 260.100 & 0 & 1.980 .000 \\
(liter/hari) & 3 & 0 & 0 & 0 & 0 & 3 \\
Pestisida (botol) & 0 & 0 & 2.700 & 2.700 & 0 & 6.000 \\
Pakan (Kg) & 225 & 400 & 0 & 0 & 0 & 500 \\
Pupuk (Kg) & 0 & 0 & 1 & 0 & 0 & 2 \\
Vaksin (Kali) & & & & &
\end{tabular}


Terdapat 7 fungsi kendala dalam penelitian ini yaitu luas lahan tiap variabel, kebutuhan tenaga kerja, kebutuhan air, kebutuhan vaksin, kebutuhan pakan, kebutuhan pestisida, dan kebutuhan pupuk. Fungsi kendala tersebut dilambangkan dengan $\left(\mathrm{a}_{\mathrm{i}}\right)$. Data untuk fungsi kendala dapat diihat pada Tabel 3.

Jadi berdasarkan Tabel 3., maka model matematik dari fungsi kendala dapat diituliskan sebagai berikut:
Pada linear programming results dapat dilihat bahwa apabila pengelolaan Lab. LT. dengan nilai maksimum $\mathrm{x}_{2}$ sama dengan nol (0), maka akan memperoleh keuntungan maksimal jika luas lahan usaha $\left(\mathrm{x}_{1}\right)$ ditambah $1 \%$ dari luas lahan sebelumnya dan untuk kolam ikan $\left(\mathrm{x}_{2}\right)$ ditambah $2,22 \%$ dari luas kolam yang digunakan sebelumnya. Jadi untuk memperoleh nilai maksimum luas lahan usaha seharusnya $13.305,74 \mathrm{~m}^{2}$ dan untuk luas kolam seharusnya

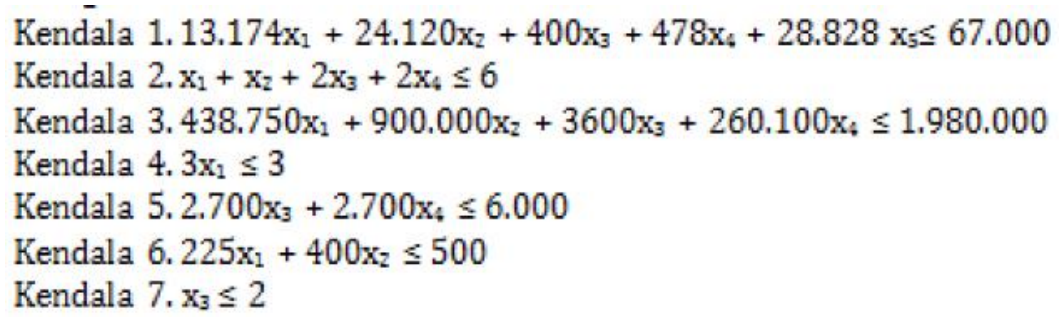

\subsection{Penyelesaian Masalah Linear Programming Optimalisasi Lab. LT Dengan Software QM For Windows}

Hasil perhitungan data analisis optimalsasi pengelolaan Lab. LT berdasarkan metode linear programming dengan bantuan softwere QM For Windows terlihat pada Gambar 2.
$488,6 \mathrm{~m}^{2}$. Bila diterapkan model tersebut maka akan diperoleh keuntungan yaitu Rp.39.703.330.

Pernyataan reduced cost menurut Motoh (2015) yaitu besarnya perubahan nilai optimal fungsi tujuan jika produk yang mestinya tidak diproduksi tetap diproduksi, hanya berlaku

\begin{tabular}{|c|c|c|c|c|c|c|c|c|}
\hline \multicolumn{8}{|l|}{ - Linear Programming Results } & $00 \times$ \\
\hline \multicolumn{9}{|c|}{ Optimalisasi pengelolaan Lab. LT. Solution } \\
\hline & $\mathrm{X} 1$ & $X_{2}$ & $x 3$ & $X 4$ & X5 & & RHS & Dual \\
\hline Maximize & 9370000 & 0 & 7581800 & 13650000 & 0 & & & \\
\hline Luas lahan (m2) & 13174 & 24120 & 400 & 478 & 28828 & $<=$ & 67000 & 0 \\
\hline Tenaga Kerja (orang) & 1 & 1 & 2 & 2 & 0 & $<=$ & 6 & 0 \\
\hline Kebutuhan Air (liter/hari) & 438750 & 900000 & 3600 & 260100 & 0 & $\Leftrightarrow$ & 1980000 & 0 \\
\hline Pestisida (botol) & 3 & 0 & 0 & 0 & 0 & $\Leftrightarrow$ & 3 & 3123333,0 \\
\hline Pakan (Kg) & 0 & 0 & 2700 & 2700 & 0 & $<=$ & 6000 & 5055,56 \\
\hline Pupuk (Kg) & 225 & 400 & 0 & 0 & 0 & $\Leftrightarrow$ & 500 & 0 \\
\hline Vaksin (Kali) & 0 & 0 & 1 & 0 & 0 & $\Leftrightarrow$ & 2 & 0 \\
\hline Solution & 1 & 0 & 0 & 2,22 & 0 & & 39703330 & \\
\hline
\end{tabular}

Gambar 2. Tampilan Linear Programming Result

\begin{tabular}{|c|c|c|c|c|c|}
\hline \multicolumn{5}{|c|}{ Ranging } & 0 - \\
\hline \multicolumn{6}{|c|}{ Optimalisasi pengelolaan Lab. LT. Solution } \\
\hline Variable & Value & Reduced Cost & Original Val & Lower Bound & Upper Bound \\
\hline $\mathrm{X} 1$ & 1 & 0 & 9370000 & 1 & Infinity \\
\hline $\mathrm{X} 2$ & 0 & 0 & 0 & -Infinity & 0 \\
\hline $\mathrm{X} 3$ & 0 & 6068200 & 7581800 & -Infinity & 13650000 \\
\hline $\mathrm{X} 4$ & 2,22 & 0 & 13650000 & 7581800 & Infinity \\
\hline \multirow[t]{2}{*}{$\mathrm{x} 5$} & 0 & 0 & 0 & -Infinity & 0 \\
\hline & Dual Value & Slack/Surplus & Original Val & Lower Bound & Upper Bound \\
\hline Luas lahan (m2) & 0 & 52763,78 & 67000 & 14236,22 & Infinity \\
\hline Tenaga Kerja (orang) & 0 & .56 & 6 & 5,44 & Infinity \\
\hline Kebutuhan Air (liter/hari) & 0 & 963250 & 1980000 & 1016750 & Infinity \\
\hline Pestisida (botol) & 3123333,0 & 0 & 3 & 0 & 4,67 \\
\hline Pakan (Kg) & 5055,56 & 0 & 6000 & 0 & 6750 \\
\hline Pupuk (Kg) & 0 & 275 & 500 & 225 & Infinity \\
\hline Vaksin (Kali) & 0 & 2 & 2 & 0 & Infinity \\
\hline
\end{tabular}

Gambar 3. Hasil Ranging 
untuk produksi suatu produk. Jika diaplikasikan untuk pengelolaan Lab. Lapang berdasarkan data hasil ranging diatas yaitu besarnya perubahan nilai optimal fungsi tujuan jika lahan yang mestinya tidak dikelola tetep dikelola. Jadi apabila suatu lahan memiliki nilai reduced cost yang lebih besar dari nol (0) maka pengelolaan lahan tersebut tidak menguntungkan. Namun jika nilai reduced cost sama dengan nol ( 0 ) berarti pengelolaan lahan tersebut masih menguntungkan.

Analisis dual dilakukan untuk mengetahui penilaian terhadap kebutuhan pengelolaan yang tersedia dan proses pengelolaan dengan melihat nilai slack dan niai dual valuenya. Jika nilai slack lebih besar dari nol dan nilai dualnya sama dengan nol maka kebutuhan untuk pengelolaan lahan dikategorikan sebagai kebutuhan yang bersifat berlebih atau tidak menjadi kendala. Sedangkan jika nilai slack dan nilai dualnya sama dengan nol maka penambahan atau pengurangan kebutuhan untuk pengelolaan tidak berpengaruh terhadap solusi optimalnya.

Nilai lower bound dan upper bound digunakan untuk melakukan analisis sensitivitas. Batas bawah (lower bound) menunjukan besarnya nilai penurunan ketersediaan bahan baku yang tidak mengubah solusi optimum awal. Batas atas (upper bound) menunjukan nilai peningkatan yang tidak akan merubah solusi optimum awal. Hasil analisi ranging tersebut menunjukan nilai lower bound (batas penurunan) dan upper bound (batas kenaikkannya) untuk lahan usaha, lahan penelitian dan praktikum, lahan ternak, kolam ikan dan lahan tidak terpakai yang diijinkan yaitu sebesar:

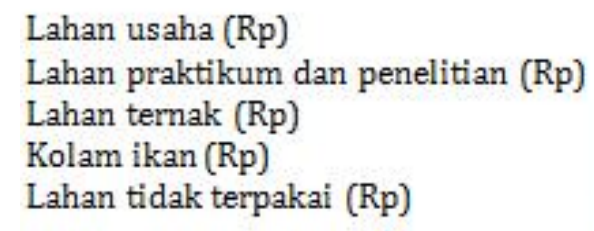

Berdasarkan nilai tersebut, berarti nilai koefisiennya bisa diubah sesuai dengan batas penurunan dan batas kenaikan yang dianjurkan karena pada rentang nilai koefisien fungsi tujuan ini tidak akan merubah nilai optimalnya.

Penggunaan luas lahan masih belum optimal karena persediaan maksimumnya sebesar
$67.000 \mathrm{~m}^{2}$ dan masih memiliki sisa sebesar $52.763,78 \mathrm{~m}^{2}$, yang digunakan hanya $14.236,22$ $\mathrm{m}^{2}$. Penggunaan tenaga kerja masih ada sisa, dari maksimum penggunaannya 6 orang dan masih sisa 1 orang, jadi hanya digunakan 5 orang saja. Penggunaan air juga masih belum optimal, karena dari persediaan maksimumnya 1.980 .000 liter/hari, masih memiliki sisa 963.250 liter/hari, jadi yang digunakan hanya 1.016.750 liter/hari. Pupuk memiliki ketersediaan maksimum $500 \mathrm{~kg}$ dan masih memiiki sisa $275 \mathrm{~kg}$, masih belum optimal karena yang digunakan hanya sebesar $225 \mathrm{~kg}$. Begitu juga dengan ketersediaan vaksin yang memiliki sisa sama dengan jumlah ketersediaan maksimum yang ada, yang berarti tidak ada penggunaan vaksin. Sedangkan untuk pestisida dan pakan tidak memiliki sisa, sehingga telah digunakan secara optimal.

Fungsi kendala luas lahan yang digunakan memiliki batas minimum penurunan (lower bound) $14.236,22 \mathrm{~m}^{2}$, dengan batas kenaikan (upper bound) tidak terbatas. Batas minimum ketersediaan tenaga kerja yaitu 5 pekerja dengan batas kenaikan tidak terbatas. Kebutuhan sumber daya air juga memiliki batas kenaikan yang tidak terbatas dan memiliki batas penurunan 1.016.750 liter/hari. Lalu untuk batas maksimum kenaikan penggunaan pestisida yaitu 4,67 botol dan untuk batas maksimum persediaan pakan yaitu $6.750 \mathrm{~kg}$. pestisida dan pakan memiliki batas minimum ketersediaan sama yaitu 0 . Pupuk memiliki batas minimum ketersediaan yaitu $225 \mathrm{~kg}$ dan untuk ketersediaan minimum vaksin yaitu nol ( 0 ) yang berarti tidak harus ada ketersediaan minimumnya, sedangkan untuk batas

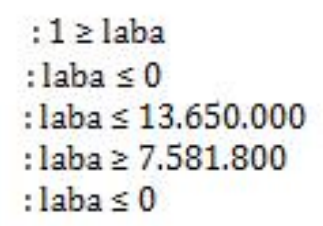

maksimum ketersediaan pupuk dan vaksin yaitu tidak terbatas. Hal tersebut tidak berarti bahwa Lab. LT dapat menyediakan kebutuhan pengelolaan lahan dengan tidak terbatas, Lab. LT harus tetap memilki batas-batas tertentu sesuai dengan kebutuhan. 
Setelah diketahui hasil analisis data asli pengelolaan Lab. LT, maka dilakukan analisis data asumsi yang akan digunakan sebagai pembanding data asli.

Pada linear programming results apabila pengelolaan Lab. LT. nilai maksimum (Zmax) $\mathrm{x}_{2}$ tidak sama dengan nol (0), maka keuntungan yang diperoleh lebih besar dibanding dengan data yang nilai maksimum (Zmax) $\mathrm{x}_{2}$ sama dengan nol. Jika berdasarkan data tersebut maka Lab. LT akan memperoleh keuntungan maksimal apabila luas lahan penelitian dan praktikum ditambah $1,25 \%$ dari luas lahan sebelumnya dan untuk kolam ikan ditambah 2,22\% dari luas kolam yang digunakan sebelumnya. Jadi apabila diterapkan model tersebut maka keuntungan yang akan diperoleh yaitu Rp. 51.333.330.
Berdasarkan data hasil ranging diatas terlihat bahwa nilai reduced cost yang sudah optimum dan menguntungkan untuk dikelola yaitu nilai pada varabel $\mathrm{x}_{2} \mathrm{x}_{4}$ dan $\mathrm{x}_{5}$ karena variabel tersebut bernilai nol (0). Sedangkan nilai reduced cost untuk variabel $\mathrm{x}_{1}$ dan variabel $\mathrm{x}_{3}$ lebih besar dari nol (0) sehingga pengelolaan kedua variabel tersebut kurang optimal untuk dikelola. Nilai hasil analisis dual terlihat sama dengan data sebelumnya yaitu nilai slack lebih besar dari nol dan nilai dualnya sama dengan nol atau sebaliknya. Jadi kebutuhan bahan baku pengelolaannya termasuk kendala yang tidak habis dipakai dalam proses pengelolaan dan tidak mempengaruhi fungsi tujuan jika terjadi penambahan.

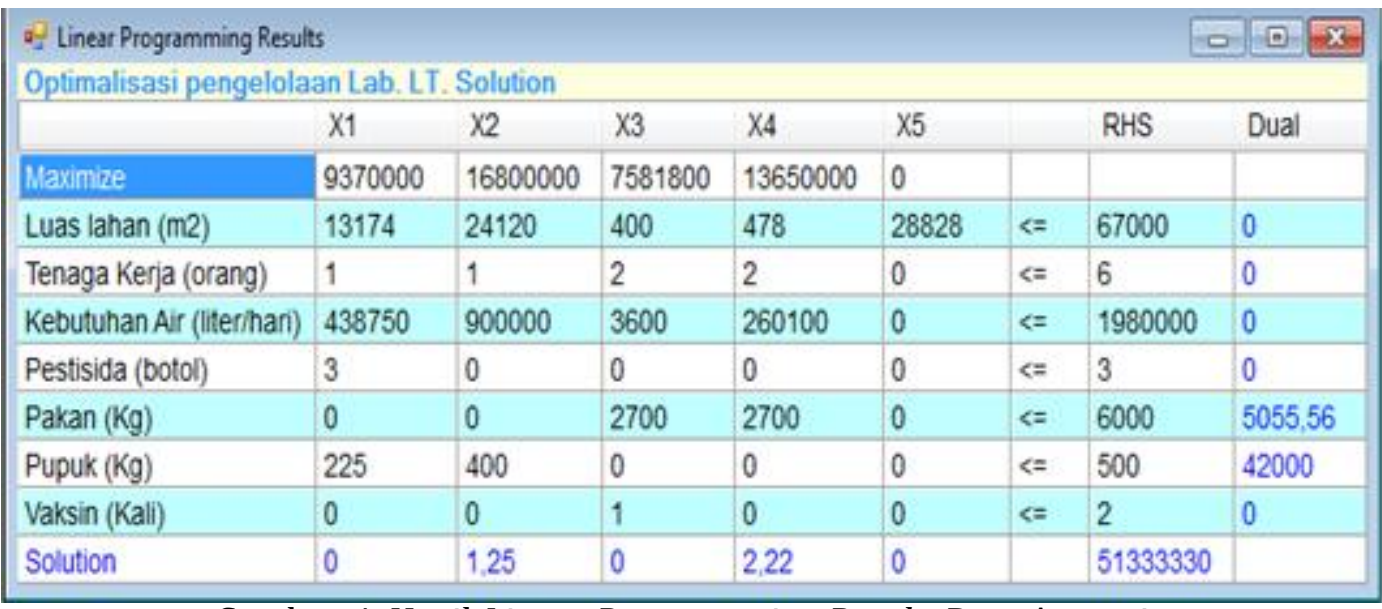

Gambar 4. Hasil Linear Programming Results Data Asumsi

\begin{tabular}{|c|c|c|c|c|c|}
\hline \multicolumn{5}{|l|}{ Ranging } & $0 \sqrt{x^{3}}$ \\
\hline \multicolumn{6}{|c|}{ Optimalisasi pengelolaan Lab. LT. Solution } \\
\hline Variable & Value & Reduced Cost & Original Val & Lower Bound & Upper Bound \\
\hline $\mathrm{X} 1$ & 0 & 80000 & 9370000 & -Infinity & 9450000 \\
\hline $\mathrm{X} 2$ & 1,25 & 0 & 16800000 & 16657780 & Infinity \\
\hline $\mathrm{X} 3$ & 0 & 6068200 & 7581800 & -Infinity & 13650000 \\
\hline $\mathrm{X} 4$ & 2,22 & 0 & 13650000 & 7581800 & Infinity \\
\hline \multirow[t]{2}{*}{$\mathrm{X} 5$} & 0 & 0 & 0 & -Infinity & 0 \\
\hline & Dual Value & Slack/Surplus & Original Val & Lower Bound & Upper Bound \\
\hline Luas lahan (m2) & 0 & 35787,78 & 67000 & 31212,22 & Infinity \\
\hline Tenaga Kerja (orang) & 0 & .31 & 6 & 5.69 & Infinity \\
\hline Kebutuhan Air (Iiter/hari) & 0 & 277000 & 1980000 & 1703000 & Infinity \\
\hline Pestisida (botol) & 0 & 3 & 3 & 0 & Infinity \\
\hline Pakan $(\mathrm{Kg})$ & 5055.56 & 0 & 6000 & 0 & 6412,5 \\
\hline Pupuk (Kg) & 42000 & 0 & 500 & 0 & 622,22 \\
\hline Vaksin (Kali) & 0 & 2 & 2 & 0 & Infinity \\
\hline
\end{tabular}

Gambar 5. Hasil Ranging Data Asumsi 
Hasil analisi tersebut menunjukan nilai lower bound (batas penurunan) untuk lahan usaha yang diijinkan infinity (tidak terbatas) dan nilai upper bound (batas kenaikannya) yaitu Rp.9.450.000, artinya keuntungan dari pengelolaan lahan tersebut penurunannya tidak terbatas dan batas kenaikkannya yaitu Rp.9.450.000. Lahan penelitian dan praktikum batas penurunannya yaitu Rp.16.657.780 dan untuk batas kenaikannya tidak terbatas. Nilai penurunan untuk pengelolaan ternak yaitu tidak terbatas dan untuk batas kenaikan atau nilai keuntungan maksimalnya yaitu Rp.13.650.000. Sedangkan untuk pengelolaan kolam ikan batas penurunannya yaitu Rp.7.581.800 dan untuk nilai kenaikannya tidak terbatas. Terakhir yaitu untuk lahan tidak terpakai memiliki batas penurunan tidak terbatas dengan batas kenaikannya yaitu nol, hal tersebut dikarenakan lahan tidak terpakai tidak berpengaruh terhadap fungsi kendakala yang ada. Berdasarkan nilai tersebut, berarti nilai koefisiennya bisa diubah sesuai dengan batas penurunan dan batas kenaikan yang dianjurkan sesuai dengan rentang penurunan dan kenaikkannya. Karena pada rentang nilai koefisien fungsi tujuan ini tidak akan merubah nilai optimalnya.

Penggunaan luas lahan masih belum optimal karena persediaan maksimumnya sebesar $67.000 \mathrm{~m}^{2}$ dan masih memiliki sisa sebesar $35.787,78 \mathrm{~m}^{2}$, dalam hal tersebut selama ini yang digunakan secara maksimal hanya $31.212,22$ $\mathrm{m}^{2}$. Penggunaan air juga masih belum optimal, dari persediaan maksimum 1.980.000 liter/hari, yang digunakan hanya 1.703.000 liter/hari dan masih memiliki sisa 277.000 liter/hari. Pestisida memiliki ketersediaan maksimum 3 botol dan masih memiiki sisa 3 botol, jadi masih belum optimal karena sama saja tidak ada yang terpakai. Begitu juga dengan ketersediaan vaksin yang masih memiliki sisa sama dengan jumlah ketersediaan maksimum yang ada, yang berarti tidak ada penggunaan vaksin. Namun untuk penggunaan pakan dan pestisida sudah optimal, karena habis terpakai. Sama halnya dengan kebutuhan tenaga kerja yang hanya memiliki sisa 0,31 orang, yang dalam pembulatannya berarti 0 atau tidak memiliki sisa.

Pada tampilan ranging memperlihatkan nilai penurunan dan kenaikan variabel dari koefisien fungsi kendala yang diijinkan. Luas lahan memiliki batas minimum penurunan 31.1212,22 $\mathrm{m}^{2}$ dengan batas kenaikan yang tidak terbatas. Penurunan batas minimum ketersediaan tenaga kerja yaitu 6 pekerja dengan batas kenaikkan maksimum tidak terbatas. Kebutuhan sumber daya air memiliki batas penurunan 1.703 .000 liter/hari dan maksimum kenaikkannya tidak terbatas. Batas minimum penurunan kebutuhan pestisida yaitu nol yang berarti tidak harus ada batas minimumnya, dan memiliki batas kenaikkannya yang tidak terbatas. Lalu batas minimum ketersediaan pakan yaitu nol dan memiliki batas kenaikkan $6.412,5 \mathrm{~kg}$. Sedangkan untuk pupuk batas minimum ketersediaannya yaitu $0 \mathrm{~kg}$ dengan maksimum ketersediaan $622,22 \mathrm{~kg}$, dan yang terakhir yaitu vaksin dengan ketersediaan minimumnya nol ( 0 ) yang berarti tidak harus ada ketersediaan minimumnya dan dengan kenaikkan ketersediaan maksimum yang tidak terbatas.

Hasil dari analisis data asli dengan data asumsi pada dasarnya sama, hanya berbeda pada perbandingan nilai keuntungan dan penambahan luas lahan optimumnya saja. Jadi untuk hasil iteration, solution list, dan dual tidak jauh beda dengan hasil sebelumnya. Data hasil iteration, solution list, dan dual dapat dilihat pada tabel lampiran. Perbedaan hasil keuntungan dari data asli dan data asumsi cukup jauh yaitu sebesar Rp.11.630.000 untuk satu semester atau setara dengan 6 bulannya.

\section{KESIMPULAN DAN SARAN}

\subsection{Kesimpulan}

Berdasarkan hasil penelitian ini maka dapat disimpulkan bahwa :

1. Rumus matematik untuk nilai Zmax data asli dan data asumsi yaitu $Z \max =3.815 .000 \mathrm{x}_{1}+0$ $\mathrm{x}_{2}+3.788 .400 \mathrm{x}_{3}+9.100 .000 \mathrm{x}_{4}+0 \mathrm{x}_{5}$ dan $\mathrm{Zmax}=3.815 .000 \mathrm{x}_{1}+16.800 .000 \mathrm{x}_{2}+$ $3.788 .400 \mathrm{x}_{3}+9.100 .000 \mathrm{x}_{4}+0 \mathrm{x}_{5}$.

2. Jika pola pengelolaan Lab. LT. dilakukan penambahan untuk luas lahan usaha $\left(\mathrm{x}_{1}\right)$ ditambah $1 \%$ dari luas lahan sebelumnya dan untuk kolam ikan $\left(\mathrm{x}_{4}\right)$ ditambah 2,22\% dari luas kolam yang digunakan sebelumnya, maka Lab. LT. akan memperoleh keuntungan setiap 6 bulannya sebesar Rp.39.703.330. 
3. Apabila yang melakukan praktikum di Lab. LT. dikenakan biaya pengelolaan sebesar Rp.500.000 per kelasnya dan untuk yang penelitian dikenakan biaya pengelolaan sebesar Rp.100.000 per orangnya, dengan menggunakan pola pengelolaan untuk luas lahan penelitian dan praktikum $\left(\mathrm{x}_{2}\right)$ ditambah $1,25 \%$ dan untuk kolam ikan $\left(\mathrm{x}_{4}\right)$ ditambah $2,22 \%$ dari luas kolam yang digunakan sebelumnya, mka Lab. LT. akan memperoleh keuntungan setiap 6 bulannya sebesar Rp.51.333.330.

\subsection{Saran}

Sebaiknya dalam penggunaan lahan sebagai tempat penelitian dan praktikum diterapkan biaya oprasional yang sesuai untuk pengelolaan laboratorium lapang terpadu, sehingga memungkinkan untuk meningkatkan pendapatan.

\section{DAFTAR PUSTAKA}

Arsil, P., dan Wijaya, K. 2009. Optimasi Tata Guna Lahan Untuk Tanaman Sayuran Di Desa Serang Kecamatan Karangreja Menggunakan Program Linier. Jurnal Matematika. Unsoed .Purwokerto.

Motoh, T. E. S. F. 2015. Implementasi Program Linear Untuk Memaksimumkan Keuntungan Produksi Bakpia Dengan Menggunakan Aplikasi POM QM. (Sekripsi). Universitas Sanata Dharma Yogyakarta.

Muhaimin, M. dan Pamungkas, A. 2014. Optimalisasi Penggunaan Lahan Untuk Memaksimalkan Pendapatan Pemerintah Daerah Kabupaten Sidoarjo. Jurnal Teknik Pomits. Vol. 3(2):87-91.

Siang, J. J. 2014. Riset Operasional Dalam Pendekatan Algoritmis. CV. Andi Offset. Yogyakarta. $354 \mathrm{hlm}$.

Wijayanto, P. 2007. Panduan Program Aplikasi QM For Windows. Fakultas Ekonomi. Universitas Kristen Satya Wacana. Salatiga. $45 \mathrm{hlm}$.
Yamit, Z. 2012. Manajemen Kuantitatif Untuk Bisnis (Operations research). BPFE. Yogyakarta. $552 \mathrm{hlm}$. 
Optimalisai pengelolaan usaha.... (Wahyu R, Sandi A, Winda R, Agus H dan Dwi DD) 